\title{
Object-Based Geomorphological Mapping: Application on an Alpine Deep-Seated Gravitational Slope Deformation Contest (Germanasca Valley, Western Alps-Italy)
}

\author{
Maria Gabriella Forno ${ }^{1}$ D, Giandomenico Fubelli ${ }^{1}$, Marco Gattiglio ${ }^{1}$, Glenda Taddia ${ }^{2, *(D)}$ \\ and Stefano Ghignone ${ }^{1}$ (D)
}

1 Department of Earth Sciences, Università degli Studi di Torino, Turin, Via Valperga Caluso 35, 10125 Torino, Italy; gabriella.forno@unito.it (M.G.F.); giandomenico.fubelli@unito.it (G.F.); marco.gattiglio@unito.it (M.G.); s.ghignone@unito.it (S.G.)

2 Department of Environment, Land and Infrastructure Engineering (DIATI), Politecnico di Torino, Corso Duca degli Abruzzi 24, 10129 Torino, Italy

* Correspondence: glenda.taddia@polito.it; Tel.: +39-011-090-7702 or +39-348-019-7717

check for

updates

Citation: Forno, M.G.; Fubelli, G.;

Gattiglio, M.; Taddia, G.; Ghignone, S.

Object-Based Geomorphological

Mapping: Application on an Alpine

Deep-Seated Gravitational Slope

Deformation Contest (Germanasca

Valley, Western Alps-Italy). Appl.

Sci. 2022, 12, 778. https://doi.org/

10.3390/app12020778

Academic Editor:

Paraskevi Nomikou

Received: 9 November 2021

Accepted: 28 December 2021

Published: 13 January 2022

Publisher's Note: MDPI stays neutral with regard to jurisdictional claims in published maps and institutional affiliations.

Copyright: (C) 2022 by the authors. Licensee MDPI, Basel, Switzerland. This article is an open access article distributed under the terms and conditions of the Creative Commons Attribution (CC BY) license (https:// creativecommons.org/licenses/by/ $4.0 /)$.

\begin{abstract}
This research reports the use of a new method of geomorphological mapping in GIS environments, using a full-coverage, object-based method, following the guidelines of the new geomorphological legend proposed by ISPRA-AIGEO-CNG. This methodology is applied to a tributary valley of the Germanasca Valley, shaped into calcschist and greenschist, of the Piedmont Zone (Penninic Domain, Western Alps). The investigated sector is extensively affected by dep-seated gravitational slope deformation (DSGSD) that strongly influences the geological setting and the geomorphological features of the area. The mapping of these gravitational landforms in a traditional way creates some difficulties, essentially connected to the high density of information in the same site and the impossibility of specifying the relationships between different elements. The use of the full-coverage, object-based method instead is advantageous in mapping gravitational evidence. In detail, it allows for the representation of various landforms in the same sector, and their relationships, specifying the size of landforms, and with the possibility of multiscale representation in the GIS environment; and, it can progressively be update with the development of knowledge. This research confirms that the use of the full-coverage, object-based method allows for better mapping of the geomorphological features of DSGSD evidence compared to classical representation.
\end{abstract}

Keywords: object-based method; full-coverage geomorphological mapping; deep-seated gravitational slope deformation; Western Alps

\section{Introduction}

Traditional geomorphological mapping (TGM) is a significant tool for landscape representation, mostly used for territorial planning. Moreover, it allows for the specification of the morphological response to lithological variability and geological structure. Though the importance of geomorphological mapping is generally recognized, this traditional tool can't overcome limits such as the impossibility of completely representing landforms and their relationships due to the use of linear symbols for mapping areal landforms. In addition, traditional geomorphology, using only dimensionless symbols, is unable to specify the actual size of landforms. A geomorphological map can be considered a graphical inventory of a landscape depicting landforms and outcropping rocks. TGM mays either focus on selected landscape features, for example, only depicting the morphology of active processes, or deliver a full view on the landscape composition and its evolution [1,2].

Sketches and maps of landscapes and landforms have been fundamental methods to analyze and visualize the Earth's surface features since early geomorphological research. The widespread distribution and extended graphical capabilities of geographic information 
system (GIS) as well as the availability of high-resolution remote sensing data such as aerial and satellite imagery and digital elevation models (DEMs), or recently, by the UAV method (unmanned aerial vehicle), has led to the recent rejuvenation of the TGM method [3].

In detail, GIS is the most-used tool for drawing geomorphological maps, composed of areas, lines, and points represented through symbolization rules. Through GIS, the attributes of elementary geometric entities are used for their cartographic representation [4]. This research reports a new tool for geomorphological mapping in the GIS environment, using a full-coverage object-based method (OBM). The aim of this work is to evaluate the advantages and disadvantages of this new method and to compare it with the traditional one. Geomorphological mapping methodology is built with simple element ("object") dataset related with various kinds of class relationships (geometric, temporal, physical, geological, lithological and hierarchical) and procedures for their interpretation [4]. The polygon is the simplest geometric element that allows for a physically-based representation of a landform. By combining adjacent polygons, the whole physical surface can be represented. The decomposition and composition of the polygons, depending on the representation scale, are obtained deriving objects such as lines and points that are themselves elements of geomorphological maps with symbolic representation. The new geomorphological legend proposed by the ISPRA-AIGEO-CNG working group for geomorphological mapping distinguishes objects on the basis of the morphogenetic agent and the state of activity. All this information must be present on the table of attributes of the shape files, with the aim of giving the possibility of generating several thematic map.

The creation of a field mapping protocol that details the steps of the mapping campaign is important, as it allows the organized collection of additional information on landforms and the creation of a database for the data mapped in the field.

The mapping scale used for data recording is usually larger than the scale of the final map, in order to collect as many details in the field as possible. Consequently, map production requires a generalization of the field data. It is worth noting that medium and small-scale geomorphological maps exist, ranging from 1:100,000 to $>1: 1,000,000$ [5,6].

We apply this new methodology in the Western Alps, following the guidelines of the new geomorphological legend proposed by the ISPRA-AIGEO-CNG working group for geomorphological mapping. The use of full-coverage OBM is applied to an area extensively affected by deep-seated gravitational slope deformation (DSGSD) in the Western Alps (Rodoretto Valley). The presence in a DSGSD of peculiar gravitational landforms at a very different scale leads us to follow an object-based full-coverage methodology, in order to represent these peculiar landforms, also using different scales [7].

In the application area of the OBM, traditional field work involving a detailed geological survey produced by the authors led to good knowledge of the territory regarding the features of bedrock and Quaternary sediments, resulting in a detailed geological and geomorphological map [8-11]. A detailed traditional geomorphological survey, especially emphasizing the typical gravitational landforms of DSGSD (as minor scarps, trenches, counterscarps and doubled ridges) has been coupled in the investigated area with geomatics techniques to also study inaccessible sectors [3].

OBM is applied to the Rodoretto Valley (at altitude from $1270 \mathrm{~m}$ to $2990 \mathrm{~m}$ a.s.1.), a tributary of the Germanasca Valley, where the relationships between DSGSD evolution and glacial landforms can be evaluated (Figure 1). In detail, two examples are identified in the investigated area for use of the new OBM and comparison with the traditional one (TGM), allowing for an evaluation of its possible advantages. The two examples are located along the Cavallo Bianco ridge in the southern side of the Rodoretto Valley see Section 2.3 and around the Balma village in the Rodoretto Valley floor (see Section 2.4), respectively. 


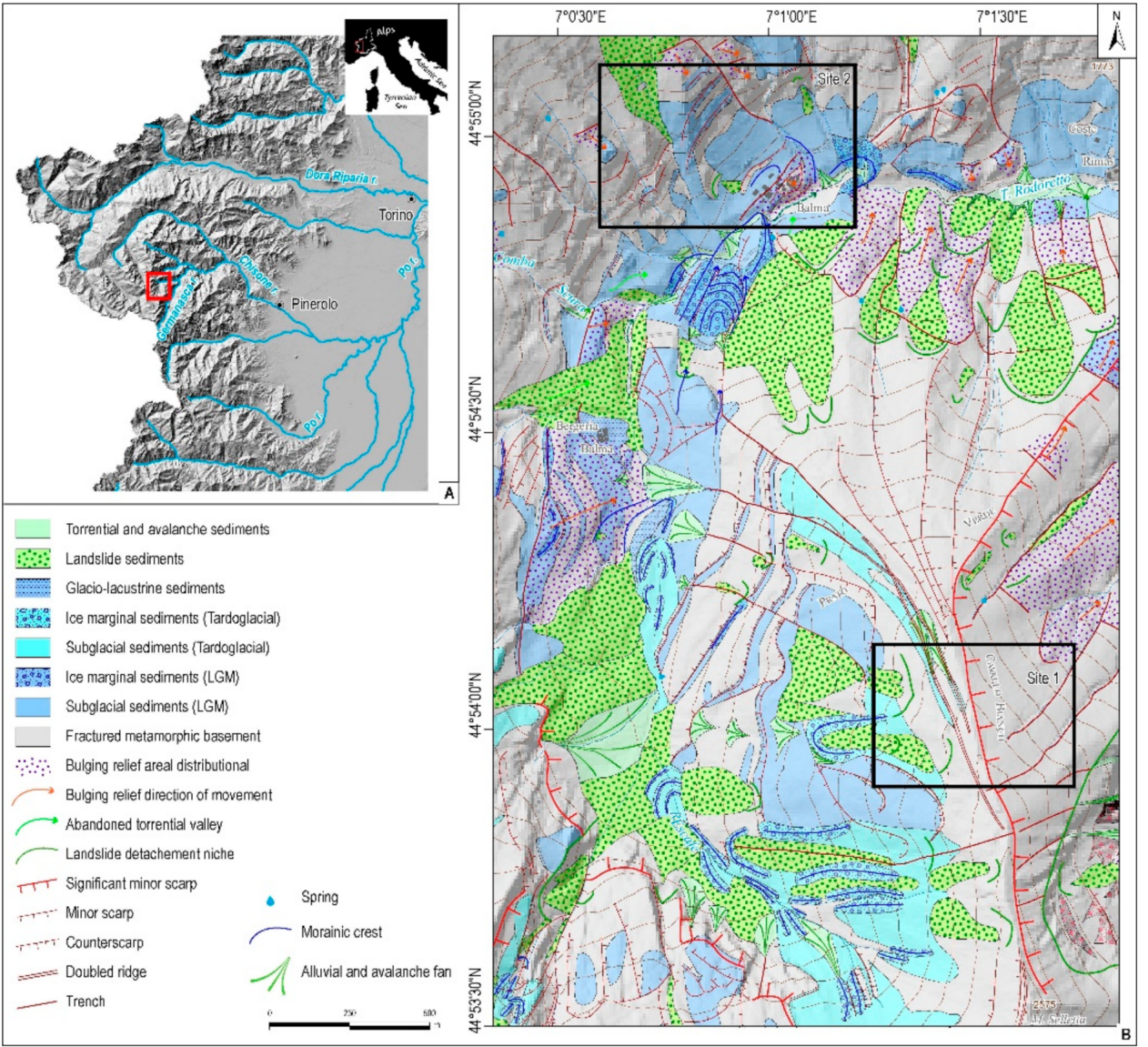

Figure 1. Geomorphological and geological sketch of the Rodoretto Valley involved by gravitational phenomena and glacial shaping (modified from [7]).

\section{Materials and Methods}

\subsection{Object-Based Method}

This paper approaches territory knowledge using a new method, described as OBM. This method is based on the principle that the entire topographic surface is mapped in terms of associated areal landforms and deposits (full coverage through polygons) defined in a hierarchical order (multiscale) and suitable to be structured in a GIS environment. It is derived directly from classic geomorphological mapping using "traditional" symbols (applied in a CARG project), of which it is an evolutionary step.

A TGM reports landforms as punctual, linear and areal symbols. The mapping of some areal landforms is through areal symbols (i.e., alluvial fan, debris fan), while other areal landforms are traditionally represented as linear symbols which refer to their edge (i.e., fluvial scarp, detachment niche). These last cases have the disadvantage that the linear symbols (i.e., the upper edge of a detachment niche) don't represent the entire areas affected by the landforms (i.e., a wide sector of the slope) and don't allow for specifying their whole spatial properties [12].

Landforms, represented in a TGM in a precise and repeatable way by the use of non-dimensional cartographic symbols, are in OBM replaced by properly demarcated surficial geometric entities represented by polygons [5,6,13-16]. This methodology, starting from a traditional geomorphological "detection", progressively refines the results of the recognition and delineation of landforms. The various steps of the method, each controlled by the expert judgment of geomorphologist, are performed by a georeferenced data analysis of a DTM in proper spacing. The collected field data can be digitalized in a GIS environment. All the geologic and geomorphologic features can be drawn as polygon type, in order to 
obtain a full-coverage map [5,6] following the object-based map criteria. The table of attributes has been generated following the hierarchic order proposed by [4].

The framework of this methodology comprises:

- Opportunity to integrate the geomorphological map with a specially dedicated database containing some landform details, not represented by "traditional" symbols (dimensions, processes, age);

- Hierarchical taxonomy whose levels are organized in terms of "topological nested entities", represented by polygons. Decreasing the scale of representation, a polygon can be mapped as lines, point symbols, backgrounds and annotations;

- Use of GIS technology that allows the production of cartographic representations that are continuously updatable, to obtain subdivisions and morphometric parameters, carry out numerical analysis and extract several thematic maps to be used, from time to time, in specific fields of application.

OBM is a methodology that can only be computerized and is not reproducible, in its entirety, in a paper version. This impossibility is connected to the multiscalarity approach, the opportunities of upgrading the data and the spatial simultaneous overlap of morphological and geological elements, not available through traditional mapping. The application of this method in the Rodoretto Valley was carried out because a large amount of geological and geomorphological data were collected by the authors, based on which a detailed geomorphological map has recently been published [17].

In detail, the methodology used for the construction of a new object-based geomorphological map is articulated in the following steps:

- Construction of a geomorphological "traditional" map and a geological map to the same scale;

- Construction of a hierarchic table of attributes in a GIS environment;

- Drawing of landforms that, on the base of the representation scale, correspond to point, polyline or polygon.

We have fixed, predefined rules of transition between hierarchical levels upwards (upscaling) and downwards (downscaling) in order to produce coherence in the multiscale mapping process and in the related geo-information.

The complexity of the gravitational landforms recognized in the investigated area suggests a use of OBM that allows for hierarchic, multi-scale representation, in order to draw the geomorphological map. All morphological objects of OBM are polygon shape files, but decreasing the scale of representation, each polygon can turn into a line. A single landform represented in a TGM can be mapped in the OBM representation with a set of polygons covering the whole landscape and accompanied by an attribute table.

In this table, different attribute fields have been generated in order to be used on the base of the representation scale. In such a way, each polygon can change the significance, varying the scale, and can comprise numerous other smaller polygons, or can be part of greater elements. Consequently, the meaning of the individual elements changes according to the used scale. For example, counterscarps at general scale can become minor scarps at local scale, and so on (see Section 2.4). The final layout of the map and the related legend will be therefore strictly connected with the representation scale.

\subsection{Detailed Material}

The object-based method is applied to the Rodoretto Valley shaped into calcschist and greenschist of the Piedmont Zone, composed by high-pressure metamorphic rocks, and located near the N-S tectonic contact with the Dora Maira Unit (Penninic Domain). The clearly prevailing calcschist shows variable composition from carbonate to phyllitic and is locally interbedded with meters-thick horizons of quartz-micaschist and micaceous marble. The greenschist forms metric to decametric isolated bodies of metabasalt, serpentinite and metagabbro [17]. 
A pervasively developed alpine metamorphic foliation, dipping towards W-WSW with low to medium dipping values, occurs. Post-metamorphic brittle deformations are also evidenced by three main tectonic fracture systems with $\mathrm{N}-\mathrm{S}, 50^{\circ} \mathrm{N}$ and $140^{\circ} \mathrm{N}$ strike, conditioning the local morphological setting. The main $\mathrm{N}-\mathrm{S}$ fracture system ubiquitously cuts out the entire area and is referred to the regional Cenischia-Nizza system (as reported in [18]). The three fracture systems show highly variable spacing, from centimetric to decametric in size: therefore, intersecting each other, these systems are responsible for the bad geomechanical conditions of the bedrock.

Wide sectors of the Rodoretto Valley floor and low slopes are covered by subglacial sediments forming grassy surfaces with typically uniform slopes representing the basal surface of the Rodoretto Glacier (blue shading in Figure 2). These sediments essentially consist of centimetric to decimetric angular clasts, with rare sub-rounded metric boulders, mixed to a subordinate sandy-silty matrix, characterized by high consolidation. The coarsegrained grain size of these sediments, normally fine, and the typical angular shape of fragments, normally rounded, is strictly connected to the strongly fractured rocks in a DSGSD contest, able to supply a great number of small-rock angular fragments $[11,19]$. The petrographic composition of the clasts essentially consists of calcschist with subordinate greenschist referred to the Rodoretto Glacier.

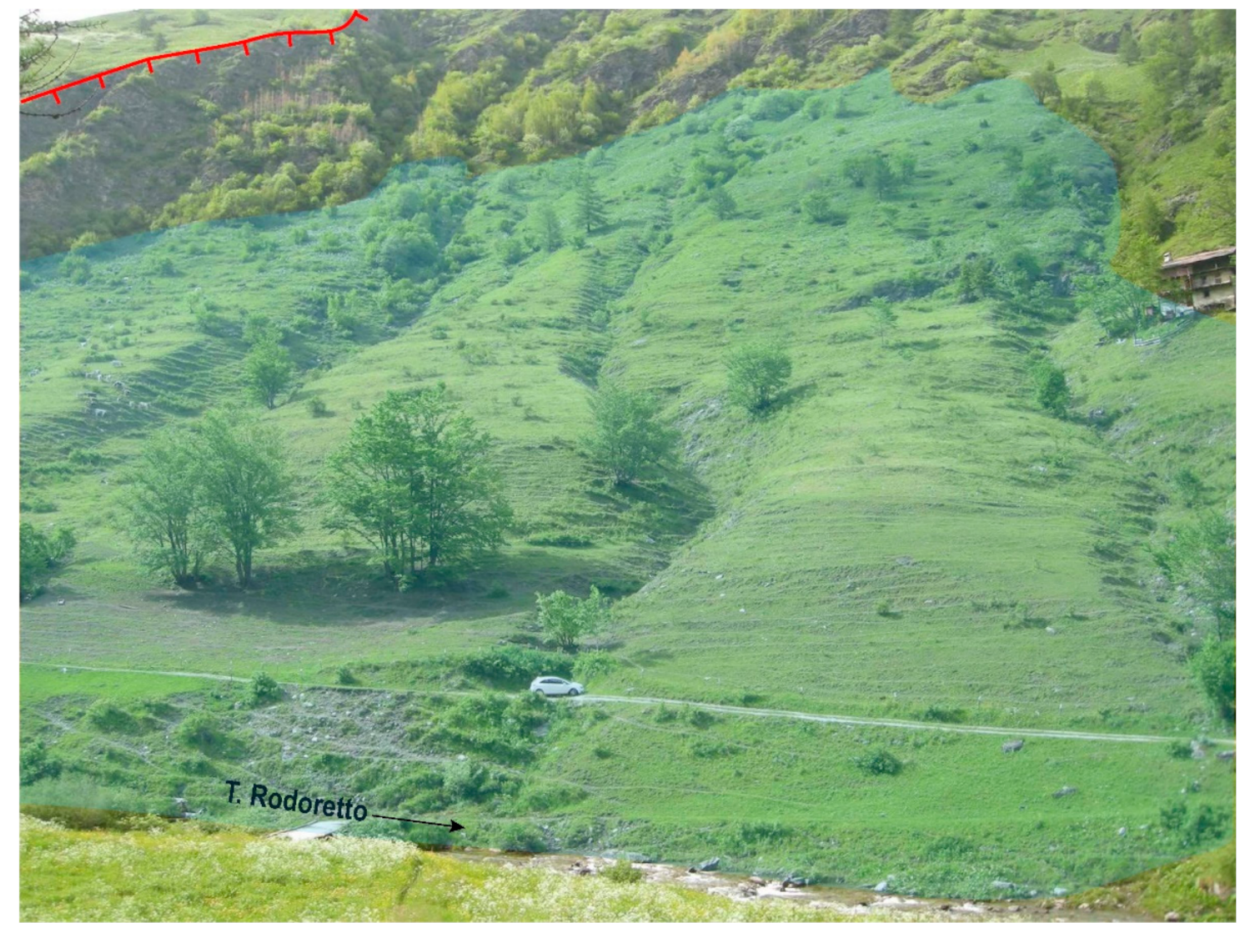

Figure 2. View of the Rodoretto Valley northern side, E of the Balma Village. It shows a rocky steep upper sector characterized by minor scarps (symbol as Figure 1) and a slightly sloping low sector (blue shading) with a cover of subglacial sediments showing typically uniform slope (grassy meadows), incised by the T. Rodoretto and the tributary watercourses.

Ice-marginal sediments are locally preserved, particularly in the moraines located near Balma village and south of Bergeria Balma (Figure 1). These sediments consist of decimetric to metric subangular clasts of calcschist, with rare greenschist linked to the Rodoretto Glacier, mixed to a subordinate, normally consolidated, sandy-silty matrix. Some small concentric moraines are, instead, preserved in the upper sector of the Rodoretto Valley and its tributaries, due to local glaciers.

Landslide accumulations are also very abundant, extensively covering the upper part of the Rodoretto Valley, formed by centimetric to metric angular clasts, essentially of calcschist, mixed to an abundant, slightly consolidated, silty-sandy matrix. The torrential 
sediments form small fans at the outlet of incisions, consisting of centimetric to decimetric sub-angular gravel, with a monotonous composition.

\subsection{Gravitational Geomorphological Features}

The area, moreover, experiences a lot of gravitational morpho-structures (doubled ridges, minor scarps, open fractures, trenches and counterscarps) typically connected to DSGSD phenomena, that at small scale essentially move rocky masses towards the main valley (i.e., Germanasca Valley). The local DSGSD movement directions, however, can be different, and developed at a different time, towards the east in the eastern Cavallo Bianco ridge, and towards the west in its western side (site 1 in Figure 1) [17]. The DSGSD phenomena in the Balma site essentially move towards the southeast (site 2 in Figure 1). The distinction between scarps and counterscarps, as shown in the following examples, was made based on the relationships between these morpho-structures and the local DSGSD movement direction. A morpho-structure is reported as minor scarp, where the gravitational surface is dipping according to the local movement direction of the DSGSD, and is reported as counterscarps, with antithetic movement. These structures are essentially developed along the three main tectonic fracture systems (N-S, $50^{\circ} \mathrm{N}$ and $\left.140^{\circ} \mathrm{N}\right)$, testifying to the strong conditioning by the previous tectonic setting and significantly dislocating both the bedrock and glacial sediments.

Doubled ridges locally develop near the Cavallo Bianco watershed according to the $\mathrm{N}-\mathrm{S}$ fracture system. Numerous minor scarps are recognized in the entire Rodoretto Valley, representing the most remarkable evidence of DSGSD (Figure 1).

The scarps are variously oriented, oblique or according to the contour lines and evidenced by sets of waterfalls along the watercourses (Figure 3). These structures cause remarkable altimetric displacements of the lithological contacts between calcschist and greenschist. Evident trenches are also visible. We can differentiate into longitudinal and transversal trenches, which develop according to the maximum slope and the contour lines, respectively [9]. These transversal trenches occur as horizontal or slightly inclined elongated close depressions. An evident transversal trench involves the glacial valley floor near the Balma village (see Section 2.4), filled by subglacial sediments.

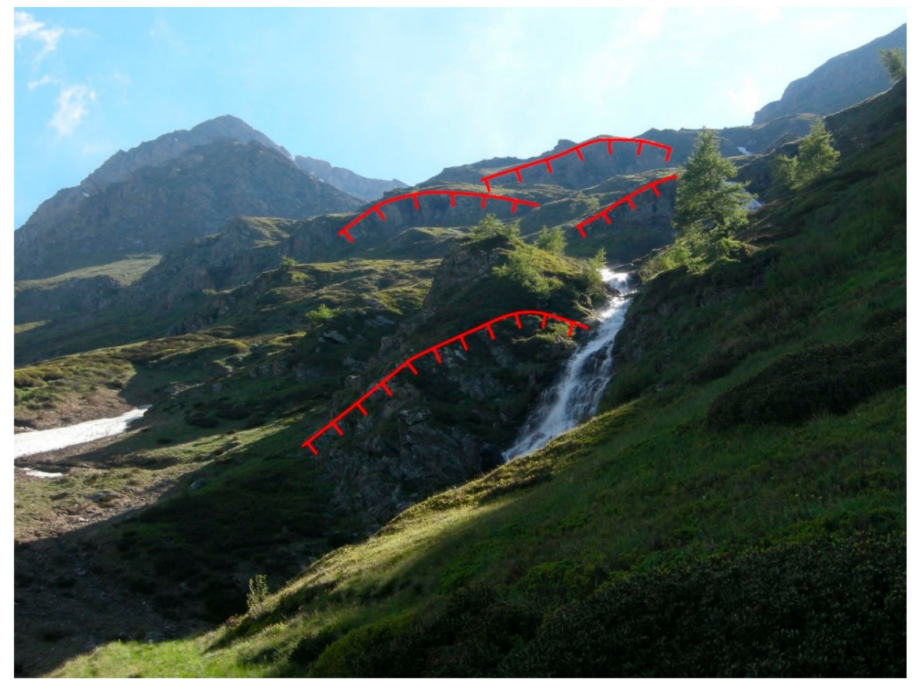

Figure 3. Evident minor scarps (symbols as Figure 1), sub-parallel to the contour lines, highlighted by waterfalls are visible in the northern side of the Rodoretto Valley.

The longitudinal trenches occur as close depressions, more difficult to identify as such for the reuse and consequent deepening by the watercourses and avalanches. They influence the hydrographic network, as visible in the Cavallo Bianco example (Figure 4). 


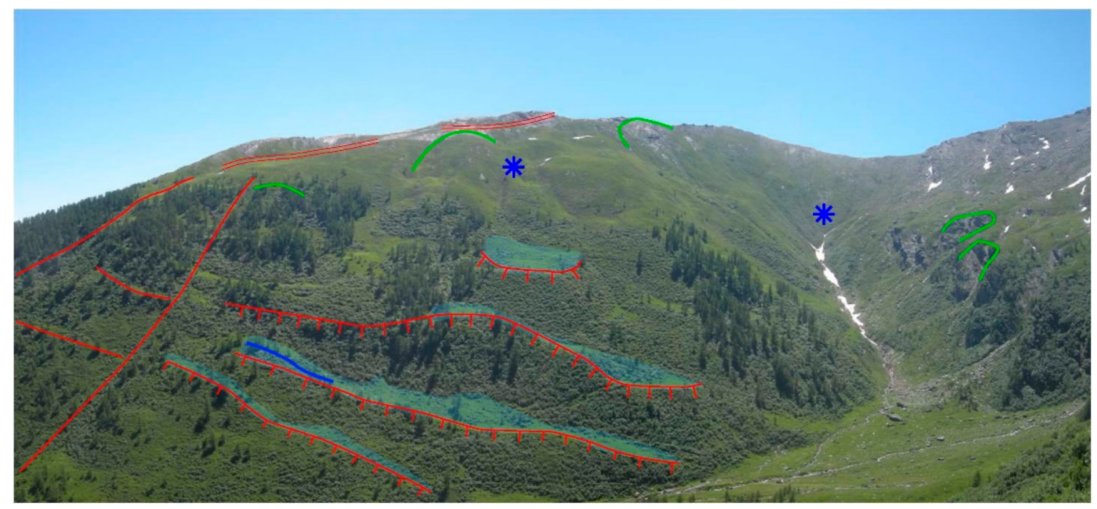

Figure 4. The Cavallo Bianco western slope shows two doubled ridges and a longitudinal trench near the watershed (symbols as Figure 1). It furthermore exhibits numerous scarps, covered by shrubs. These morpho-structures strongly dissect the flat glacial slope, only preserved as narrow grassy strips (blue shading). Depressions connected to morpho-structures promote the formation of local glaciers (asterisks). The counterslope tilting of a moraine (blue line) is the result of the differential deformations of the slope. Evident detachment niches (green lines) are also visible.

Counterscarps are also visible, dipping at the opposite way compared to the local DSGSD movement. Some counterscarps are visible along the Balma rocky relief, forming small surfaces with slope opposite to the northern side of the Rodoretto Valley (ledges) (see Section 2.4). The occurrence of depressions at different scales, essentially connected with the DSGSD minor scarps and trenches, can increase the local accumulation of snow and possibly promote the development of local glaciers, testified by well-preserved moraines (Cavallo Bianco western slope, Figure 4).

\subsection{Geomorphological Features of the Two Examples}

The first investigated example concerns the Cavallo Bianco NNW-SSE trending ridge, showing two rocky slopes affected by different DSGSD morpho-structures (Figure 1). The local DSGSD movement direction of the Cavallo Bianco western slope towards the west develops two depressions near the watershed, oriented as slope direction and shaped in the bedrock. These depressions, with lengths of approximately $1 \mathrm{~km}$ (Figures 4 and 5) and depth from some metres up to $25 \mathrm{~m}$, are referred to doubled ridges. Evident longitudinal trenches reused by avalanches represent the NW prolongation of the two doubled ridges.

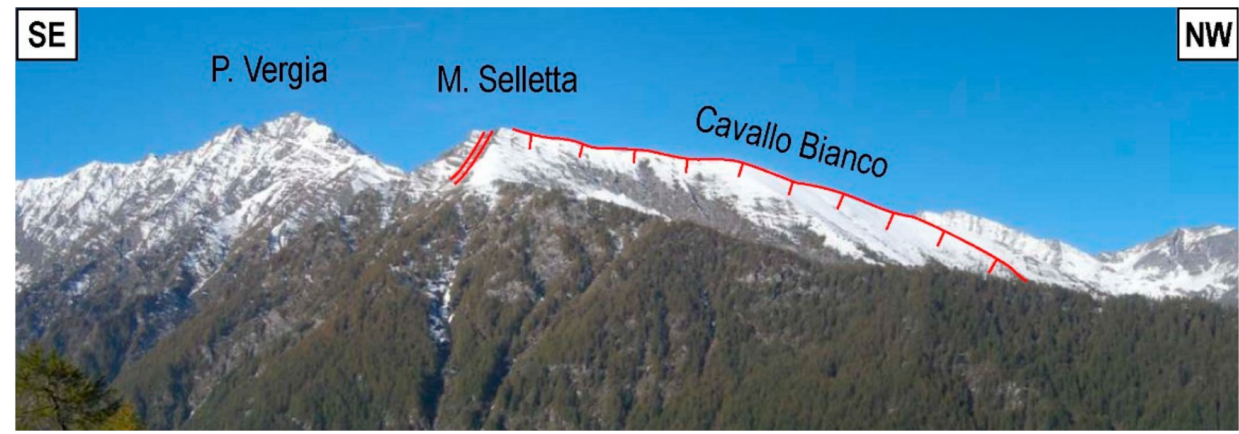

Figure 5. The Cavallo Bianco eastern slope (in the background) shows much evidence of gravitational phenomena (symbols as Figure 1). A doubled ridge is visible at M. Selletta. A sliding surface corresponding to a significant minor scarp (snowy surface) occurs $\mathrm{N}$ of M. Selletta. Numerous other minor scarps and counterscarps are, finally, visible in the foreground slope.

Moreover, scarps west-dipping with N-S and NW-SE trends, some meters high and up to $1 \mathrm{~km}$ long, occur (Figure 4), dislocating the slope covered by thin subglacial sediments. Consequently, these sediments are only preserved in narrow strips, simulating 
a set of glacial terraces (Figure 4), and tilting in counter-slope a lateral moraine (blue line in Figure 4). Small, local, now-extinct glaciers (asterisks in Figure 4) hosted in close gravitational depressions are testified by well-preserved moraines (blue line in Figure 4). Wide detachment niches are also evident (green lines in Figure 4).

The local DSGSD movement direction of the Cavallo Bianco eastern slope towards the east develops a NNW-SSE smooth surface encompassing the whole eastern slope (Figure 5). This surface can be read as morphological evidence of a significant minor scarp essentially shaped into the bedrock. It is cut by some trenches with a prevailing $50^{\circ} \mathrm{N}$ trend.

The Cavallo Bianco traditional geomorphological map (TGM) (Figure 6A) shows the distribution of the bedrock and Quaternary sediments, both dislocated by various gravitational morpho-structures. The close location of these elements (doubled ridges, minor scarps and detachment niches) near the watershed creates difficulty for their mapping. Only the main morpho-structures can be reported in a TGM and simplified as linear elements (depression of doubled ridge, edge of the minor scarp and detachment niche). The mapping of these linear elements also prevents evaluation of their real size.

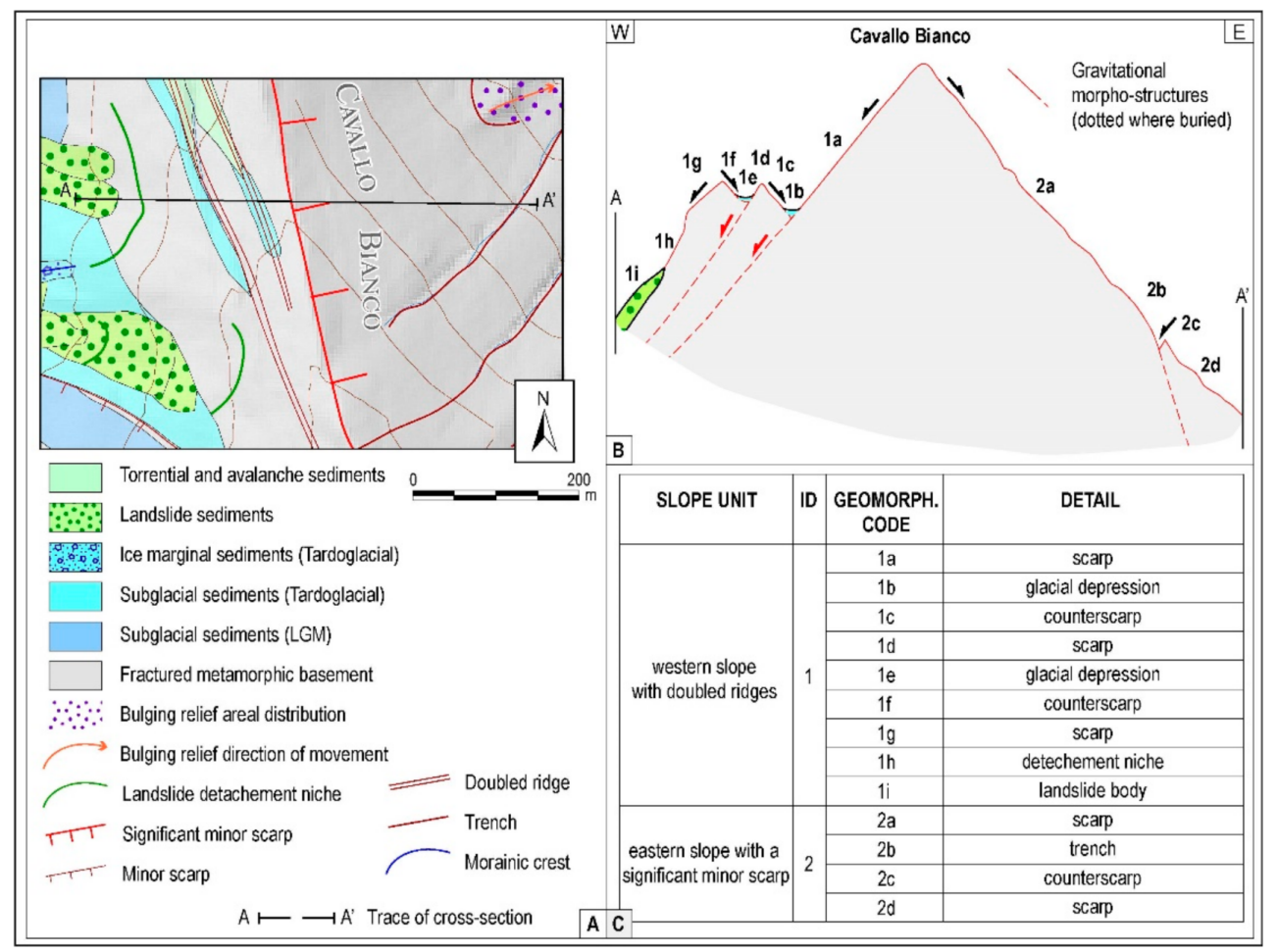

Figure 6. The Cavallo Bianco example. (A) Traditional Geomorphological Map (TGM) along the Cavallo Bianco watershed (modified from [17]). (B) Schematic cross-section related to object-based method (OBM) with the subdivision of the Cavallo Bianco ridge in polygons represented by the continuous red lines. The buried morpho-structures are reported as dotted red lines, with arrows indicating the movement direction. (C) Attribute table with the thirteen polygons 1a, 1b, 1c, 1d, 1e, 1f, $1 \mathrm{~g}, 1 \mathrm{~h}, 1 \mathrm{i}, 2 \mathrm{a}, 2 \mathrm{~b}, 2 \mathrm{c}$ and $2 \mathrm{~d}$ represented in the OBM.

By contrast, the object-based method (OBM) in a GIS environment and simplified by cross-section (Figure 6B) allows for reporting all the different morpho-structures as polygons (1a, 1b, 1c, 1d, 1e, 1f, 1g, 1h, 1i, 2a, 2b, 2c, 2d in Figure 6C) and mapping them as areal elements, with their real size. This mapping therefore favours the evaluation of the significant gravitational dislocation of the entire slope.

For example, the doubled ridges involving the Cavallo Bianco western slope, simplified in the TGM where only their axes were indicated, are instead, in this new method, represented by scarps, plunging as the maximum slope inclination (1a, $1 \mathrm{~d}$ and $1 \mathrm{~g}$ in Figure 6B) and counterscarps, oppositely plunging (1c and $1 \mathrm{f}$ in Figure 6B). Likewise, the 
significant minor scarp located on the Cavallo Bianco eastern slope is simplified in the TGM as a linear element located near the watershed and without any relation to the trench represented further down. The same morpho-structure, in the OBM method, is mapped as an areal element corresponding to the entire slope and in detail comprising some scarps ( $2 \mathrm{a}$ and $2 \mathrm{~d}$ in Figure $6 \mathrm{~B}$ ), separated by the represented trench and counterscarp (2b and 2c in Figure 6B). The attributes of each gravitational element represented in the OBM are specified in a specially dedicated database containing the landform details (Figure 6C).

The second investigated example (Figure 7) concerns a stretch of the Rodoretto Valley near the Balma village, showing an evident NE-SW trench partly filled by subglacial sediments. Moreover, the slope shows a rocky steep upper sector characterized by walls plunging towards the southeast. These walls are referred to minor scarps (Figure 7) that cut the glacial slope, preserved in strips, with subglacial sediments showing uniform slope (blue shading in Figure 7). An evident rocky relief shaped by glaciers also occurs in the medium sector (thin dashed white line in Figure 7), cut by some walls plunging towards the northwest referred to counterscarps and deeply incised in the bedrock by the T. Rodoretto (thick dashed white line in Figure 7).

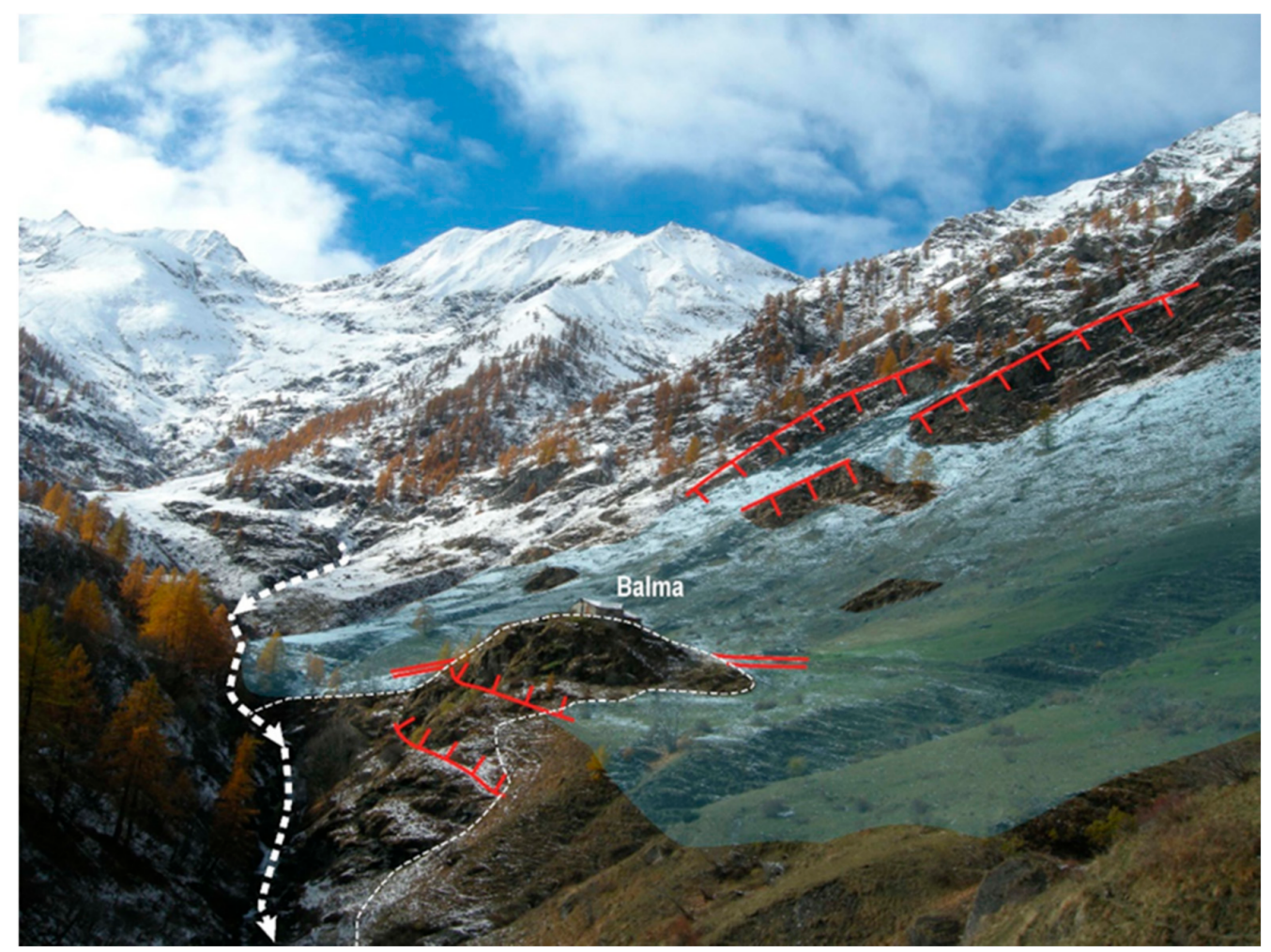

Figure 7. View of the Rodoretto Valley, left side, around the Balma Village with an evident NESW trench (symbols as Figure 1) filled by glacial sediments (blue shading). A rocky steep upper sector characterized by walls (minor scarps a) and a slightly sloping medium sector with a cover of subglacial sediments are visible. These sediments form the glacial valley floor and slope dissected by the tributary torrential incisions. An evident rocky relief (thin dashed white line) with some counterscarps, and a deep incision in the bedrock shaped by the T. Rodoretto) also occur. (thin dashed white line).

The Balma traditional geomorphological map (TGM) shows various gravitational morpho-structures dislocating the bedrock and its subglacial cover (Figure 8A). They involve the glacial slope, the glacial valley floor and the Balma rocky relief and in detail, consists of minor scarps, counterscarps and a trench. The different morpho-structures are reported as linear elements, each located at the upper edge of the single gravitational element, or along the axis, for which it is impossible evaluate their size and the relationship between 
the different morpho-structures. The close location of various morpho-structures (trench, minor scarps and counterscarps) locally creates difficulties in their complete mapping according to the scale.

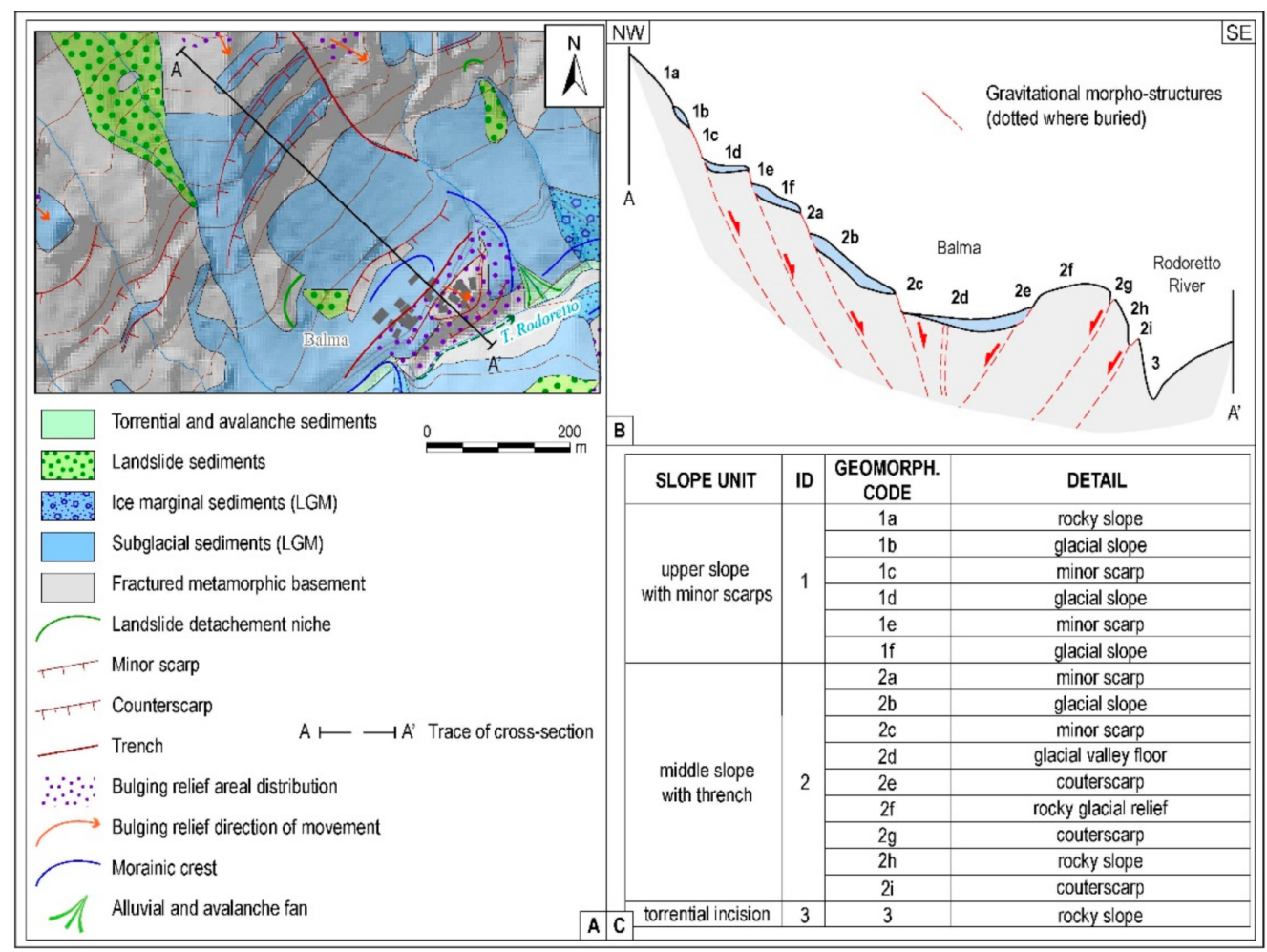

Figure 8. The Balma example. (A) Traditional geomorphological map (TGM) at the Balma village (modified from [17]). (B) Schematic cross-section, related to object-based method (OBM), of the Balma trench, with the subdivision of morpho-structures in polygons (1a, 1b, 1c, 1d, etc.) represented by continuous red lines. The buried morpho-structures are reported as dotted red lines, with arrows indicating the movement direction. (C) Attribute table with indication of the sixteen polygons 1a, $1 \mathrm{~b}$, $2 a, 2 b$, etc. represented in the OBM.

The object-based method (OBM) allows for reporting the single morpho-structures as areal elements, each represented as a polygon, mapping them with their real size. For example, the scarps involving the Balma northwestern slope, reported in the TGM as linear elements, are instead, in this new method, represented by areal scarps, plunging according to the maximum slope inclination (1c, 1e, 2a and 2c in Figure 8B), that dislocate the glacial slope in which the bedrock is covered by subglacial sediments. Similar observations can be made for the counterscarps (2e, $2 \mathrm{~g}$ and $2 \mathrm{i}$ in Figure $8 \mathrm{~B}$ ) that dislocate the Balma rocky relief ( $2 \mathrm{f}$ and $2 \mathrm{~h}$ in Figure $8 \mathrm{~B}$ ). The real dimension of scarps and counterscarps reported in the OBM favours the understanding of the significant dislocation of the entire slope. Moreover, the real dimension of the trench reported in this new method, where its axis was only indicated near the valley floor (2d in Figure $8 B$ ), partially filled by subglacial sediments, allows for an evaluation of its relationship with scarps and counterscarps. The attributes of the single gravitational elements represented in the new method are specified in a specially dedicated database containing the landform details (Figure 8C).

\section{Results and Discussion}

Geomorphological maps should exhaustively represent the landscape of an area. The symbols traditionally used cannot always reach this goal. This issue is particularly remarkable for the areas characterized by a complex morphological framework, like those involved by DSGSD. 
The traditional geomorphological map (TGM) carried out in these areas generally implies only a representation of the upper edge of a gravitational morpho-structure (i.e., the upper edge of minor scarp and detachment niche) or its axis (i.e., the depression of doubled ridge and trench), instead of the entire surface affected by the structure. Consequently, TGM does not represent the entire framework of the slope, for a series of reasons:

- A linear symbol cannot represent the entire sector affected by a morpho-structure nor specify its areal size;

- Very close-together morpho-structures usually cannot be reported, if not using a proper detailed mapping scale;

- The relationships between the different geomorphological elements cannot always be represented, except when linear symbols intersect each other.

These reasons for TGM inadequacy are well-evident in the two investigated examples, where very dense gravitational morpho-structures result in difficulties related to choosing which structure to report. In detail, the Cavallo Bianco upper western slope TGM implies a symbolic representation, only mapping the axis of doubled ridges (namely, the central depressions) (Figure 6A). The traditional mapping of these morpho-structures, despite providing information on their length, does not show the overall areal size, the encompassing of various elements (scarps, depressions and counterscarps) and their relationships. Moreover, this framework doesn't allow for a representation of the magnitude and complexity of the gravitational deformation.

The full set of geomorphological elements of this slope are instead well-distinguished in OBM in a GIS environment and simplified by cross section (Figure 6B), where different scarps, depressions and counterscarps are distinguished within the doubled ridges (polygons 1a, 1b, 1c, 1d in Figure 6C); relationships between the different morpho-structures are also evaluable. Moreover, the mapping of the upper edge of the significant minor scarp in the Cavallo Bianco upper eastern slope (Figure 6A) in TGM doesn't depict its significant areal extension. This mapping also does not offer the possibility of evaluating the relationships of the reported trench and counterscarp with the main scarp, because their symbols don't intersect each other. The use of OBM (Figure 6B), highlighted by cross section, instead solves the issue by allowing the representation of the various landforms and the relative chronology through the indication of scarp and counterscarp $(2 \mathrm{c}$ and $2 \mathrm{~d}$ in Figure 6C) that have dissected the significant minor scarp (2a and $2 b$ in Figure $6 \mathrm{C}$ ).

A second example of improvement to geomorphological cartography is in reference to the Balma site. The TGM, in this case, also implies (Figure 8A) a symbolic representation of morpho-structures, only mapping the upper edge of scarps and counterscarps and the trench axis, not paying particular attention to their relationships. On the contrary, OBM and relative cross-sections (Figure $8 \mathrm{~B}$ ) depict well the complex framework of slope (i.e., 2a, 2b, 2c, 2d, 2e, 2f, 2g, 2h, 2i in Figure 8C).

Therefore, some general considerations can be proposed through study of the two case studies. Some morpho-structures (trench and doubled ridge) of which the only axis is reported in TGM can be decomposed in different elements in OBM (scarps, depressions and counterscarps). In detail, the set of ID polygons 1, 2 etc. can be decomposed in its elementary polygons $1 \mathrm{a}, 1 \mathrm{~b}$ etc. and $2 \mathrm{a}, 2 \mathrm{~b}$, etc. in a multi-scale-related combination $[4,20-22]$.

Another consideration resulting from this research concerns the definition of the type of morpho-structure according to the observation scale. For example, a counterscarp as defined at general scale can be read as minor scarp if defined at detailed scale.

The application of these new methodologies (OBM) in the investigated sectors is advantageous and consequently is preferable to the use of traditional geomorphological mapping (TGM). With the aim of obtaining a more complete and detailed representation of the geological setting of an area, the use of OBM presents wide advantages with respect to TGM. Moreover, OBM in a GIS environment can be updated in the time with the progress of knowledge. 


\section{Conclusions}

This research reported the use of a new method of geomorphological mapping in a GIS environment, using a full-coverage, object-based method, following the guidelines of the new geomorphological legend proposed by the ISPRA-AIGEO-CNG working group on geomorphological mapping, applied to the Rodoretto Valley (Penninic Domain, Western Alps), extensively affected by DSGSD.

The representation of gravitational morpho-structures as doubled ridges, minor scarps, trenches and counterscarps in a traditional way creates some difficulties, essentially connected to local high density of information in the same site. The use of the full-coverage, object-based method facilities the mapping of gravitational morpho-structures. In detail, it allows for a representation of various landforms in the same sector, specifying the size of landforms and their relationships, also with the possibility of multiscale representation in a GIS environment, and its updating with the progress of knowledge.

Finally, the object-based method is a very useful methodology which, however, can only be computerized, and is not reproducible in its entirety in a printed version. This impossibility is connected to the multiscalarity approach, the opportunities of upgrading the data and the spatial simultaneous overlap of morphological and geological elements, not available through traditional mapping.

Author Contributions: Conceptualization, G.F., M.G.F. and M.G.; methodology, G.F. and M.G.F.; software, S.G. and G.T.; validation, G.F; investigation, M.G.F., M.G. and G.T.; resources, M.G.F., M.G. and G.T.; writing—original draft preparation, M.G.F., M.G. and G.F.; writing—review and editing, S.G. and G.T. All authors have read and agreed to the published version of the manuscript.

Funding: This research received no external funding. This research was funded by self-funded research of the Turin University (research project manager: Andrea Festa). The cost of publication was funding by research project of G.T. Politecnico di Torino.

Institutional Review Board Statement: Not applicable.

Informed Consent Statement: Not applicable.

Data Availability Statement: The data presented in this study are openly available in reference number $[3,7-11,16]$.

Conflicts of Interest: The authors declare no conflict of interest.

\section{References}

1. Smith, M.J.; Paron, P.; Griffiths, J.S. Geomorphological mapping, methods and applications. In Developments in Earth Surface Processes; Elsevier: Oxford, UK, 2011; p. 15.

2. Seijmonsbergen, A.C. The Modern Geomorphological Map. In Methods in Geomorphology; Switzer, A., Kennedy, D.M., Eds.; Elsevier: Amsterdam, The Netherlands, 2013; pp. 35-52.

3. Piras, M.; Taddia, G.; Forno, M.G.; Gattiglio, M.; Aicardi, I.; Dabove, P.; Lo Russo, S. The use of Unmanned Aerial Vehicle (UAV) for detailed geological mapping in mountain area: Test and results. Geomat. Nat. Hazards Risk 2017, 8, 137-149. [CrossRef]

4. Guida, D.; Palmieri, V.; Paron, P.; Siervo, V. The geomorphological informative mapping system (GIMS) of Salerno University: An Overview. Application to a Polygenetic Mediterranean Landscape (Cilento and Vallo di Diano European Geopark). In Proceedings of the IAG/AIG International Workshop on “Objective Geomorphological Representation Models: Breaking through a New Geomorphological Mapping Frontiere, Salerno, Italy, 15-19 October 2012; pp. 73-77.

5. Dramis, F.; Guida, D.; Cestari, A. Nature and aims of geomorphological mapping. In Geomorphological Mapping: Methods and Applications; Smith, M.J., Paron, P., Griffith, J.S., Eds.; Elsevier: Amsterdam, The Netherlands, 2011; Volume 15, pp. $39-73$.

6. Dramis, F.; Guida, D.; Cestari, A.; Siervo, V.; Palmieri, V. Dalla cartografia geomorfologica al sistema cartografico geomorfologico: Metodologie, procedure e applicazioni. Geol. Tecnia Ambient. 2011, 3, 10-25.

7. Taddia, G.; Gnavi, L.; Piras, M.; Forno, M.G.; Lingua, A.; Lo Russo, S. Landslide susceptibility zoning using GIS tools: An application in the Germanasca Valley (NW Italy). In Engineering Geology for Society and Territory Landslide Processes, Proceedings of the IAEG XII Congress 2014, Torino, Italy, 15-19 September 2015; Springer: Cham, Switzerland, 2015; Volume 2, pp. 177-181. [CrossRef]

8. Forno, M.G.; Lingua, A.; Lo Russo, S.; Taddia, G. Improving digital tools for Quaternary field survey: A case study of the Rodoretto Valley (NW Italy). Environ. Earth Sci. 2011, 64, 1487-1495. [CrossRef]

9. Forno, M.G.; Lingua, A.; Lo Russo, S.; Taddia, G. Morphological features of Rodoretto Valley deep-seated gravitational slope deformations. Am. J. Environ. Sci. 2012, 8, 648-660. [CrossRef] 
10. Forno, M.G.; Lingua, A.; Lo Russo, S.; Taddia, G.; Piras, M. GSTOP: A new tool for 3D Geomorphological survey and mapping. Eur. J. Remote Sens. 2013, 46, 234-249. [CrossRef]

11. Forno, M.G.; Gattiglio, M.; Gianotti, F.; Rossato, S.; Taddia, G. Deep-seated gravitational slope deformation effects on Quaternary deposits in the western alps (NW Italy). Alp. Mediterr. Quat. 2020, 33, 43-60. [CrossRef]

12. Drăguț, L.; Blaschkeb, T. Automated classification of landform elements using object-based image analysis. Geomorphology 2006, 81, 330-344. [CrossRef]

13. Dikau, R.; Brabb, E.E.; Mark, R.M. Landform classification of New Mexico by computer. US Department of the Interior, US Geological Survey. Open-File Rep. 1991, 91, 634.

14. Hughes, J.H. Object-Oriented Databases; Prentice Hall: Englewood Cliffs, NJ, USA, 1991; p. 602.

15. De Pippo, T.; Guida, D.; Lanzara, V.; Siervo, V.; Valente, A. Criteri, Metodi e Procedure Innovative per la Redazione di Cartografia Geomorfologica Gerarchica Multiscalare: Proposte Operative in Ambiente GIS. In Proceedings of the Convegno Nazionale AIGEO “Ambiente Geomorfologico e Attività dell'Uomo: Risorse, Rischi, Impatti”, Torino, Italy, 28-30 March 2007; pp. 230-234. (In Italian)

16. Anders, N.S.; Seijmonsbergen, A.C.; Bouten, W. Multi-scale and object-oriented image analysis of high-res LiDAR data for geomorphological mapping in Alpine Mountains. In Proceedings of the Geomorphometry, Zurich, Switzerland, 31 August-2 September 2009; pp. 61-63.

17. Forno, M.G.; Gattiglio, M.; Taddia, G.; Ghignone, S. Deep-seated gravitational slope deformation involving glacial evidence in the Rodoretto Valley (NW Alps). J. Maps 2021, 17, 846-858. [CrossRef]

18. Forno, M.G.; Massazza, G. Movimenti gravitativi diffusi e ripetuti nel versante sinistro della Val Cenischia (Alpi Graie) e loro relazione con il sistema di fratture Cenischia-Nizza. Geogr. Fis. Dinam. Quatern. 1987, 10, 277-306.

19. Forno, M.G.; Comina, C.; Gattiglio, M.; Gianotti, F.; Lo Russo, S.; Sambuelli, L.; Raiteri, L.; Taddia, G. Preservation of Quaternary sediments in DSGSD environment: The Mont Fallére case study (Aosta valley, NW Italy). Alp. Mediterr. Quat. 2016, 29, 181-191.

20. Bunn, M.; Leshchinsky, B.; Olsen, M.; Booth, A. A Simplified, Object-Based Framework for Efficient Landslide Inventorying Using LIDAR Digital Elevation Model Derivatives. Remote Sens. 2019, 11, 303. [CrossRef]

21. Zhang, J.; Wu, C.; Wang, L. A Conceptual Framework for the Automated Generalization of Geological Maps Based on Multiple Agents and Workflow. IEEE Access 2016, 4, 6374-6385. [CrossRef]

22. Sayidov, A.; Aliakbarian, M.; Weibel, R. Geological Map Generalization Driven by Size Constraints. ISPRS Int. J. Geo-Inf. 2020, 9 , 284. [CrossRef] 